\title{
Study on Coating and Luminescence Mechanism of Hydrothermal Preparation of Mica-based Pearlescent Pigments
}

\author{
Daguang Li \\ School of materials science and engineering, Northwestern Polytechnical University \\ Xi'an 710072, China \\ Faculty of chemical engineering and light industry, Guangdong University of Technology \\ Guangzhou 510006, China \\ Tel: 86-20-3932-2235_E-mail: daguangl@gdut.edu.cn \\ Chao $\mathrm{Yu}$ \\ Faculty of chemical engineering and light industry, Guangdong University of Technology \\ Guangzhou 510006, China \\ Tel: 86-20-3932-2231_E-mail: hadiyuchao@163.com \\ Tiehu Li \\ School of materials science and engineering, Northwestern Polytechnical University \\ Xi'an 710072, China \\ Weiqing Fu, Wenjin Ji \& Fenghua Zhao \\ Faculty of chemical engineering and light industry, Guangdong University of Technology \\ Guangzhou 510006, China
}

\begin{abstract}
Pearlescent pigment with the properties of high crystallinity, good dispersity, no agglomeration and smooth and crackless surface was prepared by hydrothermal method instead of calcination in the present paper. Through observation, rules of preparing high performance pearlescent pigment were obtained, described as follows: Increment of temperature and elongation of time during the period of hydrothermal reaction was beneficial to the crystallization of pearlescent pigment. Herein, coating and luminescence mechanism of pearlescent pigment was taken into further investigation.
\end{abstract}

Keywords: Mica-based pearlescent pigments, Hydrothermal synthesis, Coating mechanism, Luminescence mechanism

\section{Introduction}

Mica-based pearlescent pigment is a new kind of inorganic nonmetallic pigment with special effect which showing lustrous and iridescent due to angle-dependent optical effects deriving from alternating transparent layers with different reflection, refraction and transmission indices. It can reproduce graceful luster and colors which butterfly, shell, pearl, migratory fish and metals possess in nature. With many peculiarities which other pigments are provided with, such as pearlescent effect, metal-spark effect, perspective shot effect, color transferring effect, additional coloring effect, three dimensional effect and background contrast effect(Xu, 2005, PP. 23-26). Due to many excellent effects, mica-based pearlescent pigments are widely applied in a variety of industrial products, such as paints, ink, cosmetics, plastics, rubber and printed products(Sun, 2004, PP. 27-29).

In the producing process of mica-based pearlescent pigments, a critical point is crystallization treatment of pearlescent pigments. Currently, they are typically produced by the deposition of metal oxide layers on the substrate in aqueous suspension followed by a calcinations process(Xu, 2002, PP. 227 229, Young, 2008, PP. 213-218). The calcination of hydrous $\mathrm{TiO}_{2}$ in order to eliminate surface absorbing water, capillary pores water and crystal water results in crystalline 
$\mathrm{TiO}_{2}$. As a matter of fact, agglomeration is an cardinal limiting factor in calcination. Particles of pearlescent pigment are prone to result in hard agglomeration and thus being caked, and thermal expansion coefficient between mica plate and $\mathrm{TiO}_{2}$ thin layer is different, which have a notable influence on the dispersive property of pearlescent pigment and its optical effects.

It had been investigated that crystal materials were prepared using hydrothermal methods by geologists through simulating the natural mineralization since mid-19th century. Ever since 1905, functional materials have alternatively attracted many researchers' attention. It has been recently developed that nano-materials were prepared by hydrothermal methods(Li, 2007, PP. 1864-1868, Wang, 2007, PP. 225-230). Herein, crystal particles developed completely, granularity distributed uniformly with less agglomeration; material used was cheaper, and desirable stoichiometric composition materials could be obtained; particle size could be controlled during the process with lower production cost. Nano-powder prepared by hydrothermal methods need not calcination which could avoid the defects of agglomeration and introduced impurity.

Pearlescent pigments have been extensively applied, however, reports on the coating and luminescence mechanism were less available in the literature. In the present paper, pearlescent pigment was prepared by hydrothermal methods and the underlying coating and luminescence mechanism was also investigated.

\section{Materials and methods}

\subsection{Preparation of mica-based pearlescent pigment}

The synthetic (fluorophlogopite) mica used as the substrates for pearlescent pigment was purchased from Shantou, China. Mica powders were dissolved in certain volume of deionized water at the ratio of $1: n(n=10 \sim 30)$ and then transferred into $250 \mathrm{ml} 3$ mouth flask. Solution $\mathrm{pH}$ value was adjusted to $1.0 \sim 2.4$ with the addition of certain concentration of sulfuric acid solution. The batch was then heated in the acid solution under stirring for 30 mins. Then titanium solution with certain concentration as well as some deionized water was introduced into the agitated slurry. The slurry was stirred for 20 mins. After the completion of hydrolysis, the solids were filtered, washed with distilled water into neutral position and dried by air forced drying for $4 \mathrm{~h}$ or so at $70 \sim 110{ }^{\circ} \mathrm{C}$. The resultant precursor was undertaken hydrothermal treatment. After filtering and drying, mica-based pearlescent pigment was obtained.

\subsection{Testing and analysis}

Scanning electron microscopy(SEM) images was obtained to observe the morphological aspects of fired samples by S-3400N- II (kabushiki kaisha, Japan) with an accelerated voltage of $20 \mathrm{KV}$; zeta potential was measured by Zetaprobe Software Operators Manval(Colloidal Dynamics, USA); X-ray diffraction(XRD) patterns were obtained on a XRF spectrometry(PGENERAL, Beijing) with $\mathrm{Cu}$ Ka radiation( $40 \mathrm{KV}, 200 \mathrm{~mA}, \lambda=1.5406 \AA$ ) and $2 \theta$ range of $20 \sim 70^{\circ}$ and scan speed of $4 \% \mathrm{~min}$. According to X-ray diffraction rationale(Yang, 1989, PP. 184-189), within $2 \theta$ range, tangent was made at the lowest point, connected with the lowest point of characteristic diffraction peaks and thus amorphous scattering curve was depicted where the lower area was the integral intensity(Sa) of amorphous portion and the upper area was that $(\mathrm{Sc})$ of crystalline portion.Crystallinity Xc was calculated by the following formula:

$$
X c=\frac{S c}{S c+1.297 S a} \times 100 \%
$$

\section{Results and discussions}

\subsection{Univariate analysis of hydrothermal reaction}

Precursors of pearlescent pigment were dispersed into high-pressure reactor with deionized water and undertaken to hydrothermal reaction at certain temperature for certain time. These two factors were associated with crystallization of precursors and keeping integrity of coating membrane after dehydration process. Therefore, effects of time and temperature on the hydrothermal reaction should be investigated.

\subsubsection{Effects of time}

At the constant temperature of $240^{\circ} \mathrm{C}$, hydrothermal reactions were performed for 4,8 and $12 \mathrm{~h}$, respectively, using the same batch precursors of pearlescent pigment. Resultant powder was measured by XRD, and results were depicted with detail in Figure 1 and Table 1.

As seen from Figure 1 and Table 1, it was known that reaction time had a great influence on the crystallization of pigment, and crystallization increased with the increasing of time. Compared Figure 1 to the Joint Committee on Powder Diffraction Standards (JCPDS), crystal form of $\mathrm{TiO}_{2}$ coating mica powders was anatase with a characteristic diffraction peak at $25.28^{\circ}$ which corresponded to the crystal face $(101)$ of $\mathrm{TiO}_{2}$. Sample a was basically not crystallized. With the increasing of time, anatase $\mathrm{TiO}_{2}$ diffraction peak of sample $\mathrm{b}$ and $\mathrm{c}$ at $25.28^{\circ}$ became intensive and sharp, which indicated that the increment of reaction time was favorable to the crystallization of membrane coated by anatase $\mathrm{TiO}_{2}$. 


\subsubsection{Effects of temperature}

For the constant time of 12 , hydrothermal reactions were performed at $180^{\circ} \mathrm{C}, 210^{\circ} \mathrm{C}$ and $240^{\circ} \mathrm{C}$, respectively, using the same batch precursors of pearlescent pigment. Resultant powder was measured by XRD, and results were depicted with detail in Figure 2 and Table 2.

As seen from Figure 2 and Table 2, it was known that crystallization increased with the increasing of reaction temperature.

\subsection{Comparative analysis of hydrothermal synthesis and calcination}

Results showed that hydrothermal process was simple and could obtain more excellent powder material than calcination without high temperature sintering.Powder material with the properties of high crystallinity, good dispersity and less agglomeration could be directly prepared by hydrothermal method.

As seen from Figure 3, it was obvious that there was agglomeration among pigments with calcination(Figure 3 II ); pigments were well dispersed without any agglomeration(Figure $3 \mathrm{I}$ ). Furthermore, $\mathrm{TiO}_{2}$ membrane layer crazed due to stress concentration during the period of calcination and was easy to shed(Figure 3 IV); Pigments by hydrothermal method could efficaciously avoid stress concentration, and thus resulted in good properties of smooth and compact surface without cracking and shedding(Figure 3 III).

\subsection{Coating mechanism of pearlescent pigments}

Liquid phase deposition resulting in the precursors of mica-based pearlescent pigments belongs to the typical liquid-solid non homogeneous reaction. It is believed that mica substrate was first wetted by titanium solution, under the interaction of electrolyte solution and reaction temperature, mica flake with constant negative charge began to adsorb cationic complexes of $\left[\mathrm{Ti}\left(\mathrm{H}_{2} \mathrm{O}\right)_{6}\right]^{4+}$ resulting from the first stage of hydrolysis of $\mathrm{TiCl}_{4}$ solution, and formed a "double electrical layers" in the surface of mica flake. $\mathrm{H}^{+}$derived from $\mathrm{H}_{2} \mathrm{O}$ group of $\left[\mathrm{Ti}\left(\mathrm{H}_{2} \mathrm{O}\right)_{6}\right]^{4+}$ continuously transferred into solutions, gradually formed dimeric- or poly- complex ions of titanium, and then finally metatitanic acid particles which inhabited and developed in the surface of mica flake. Polynuclear complexes in the double electrical layers could develop any way along the solid surface. Due to the increasing of charges of polynuclear complex ions, their electrostatic attraction with the surface of mica flake increased correspondingly, which made them develop first along a certain part of the surface of mica flake and formed a "island-like coating" until coating the whole flake. Resultant complex ions develop further along the liquid surface, and thus completed the whole process of preparing titanium dioxide microcrystalline, namely a whole process of coating as follows: emergence--develop--converge--multi-layer coat(Gong, 2002, PP. 13-16).

According to the previous discussion of coating mechanism, surface electrokinetic potentials of mica flake and metatitanic acid particles at various $\mathrm{pH}$ values were measured, which were presented in Figure 5.

As seen from Figure 5, charges of mica flake and metatitanic acid particles varied at various $\mathrm{pH}$ values. Isoelectric point of metatitanic acid particles resulting from hydrolysis of $\mathrm{TiCl}_{4}$ solution is 2.68 in water, when the $\mathrm{pH}$ values in reaction ranged from 1.0 2.3, due to great difference of heterocharge and intensive electrostatic attraction between mica flake and metatitanic acid particles, particles were proned to adsorb in the surface of mica flake when they collided with mica flake due to the stirring. When $\mathrm{pH}$ value was high in reaction system, both mica flake and metatitanic acid particles carried high negative charges. Electrostatic repulsion between them exceeded the adsorbability of particles, which kept the dispersion stability of reaction system and thus hampered the deposition of metatitanic acid particles in the surface of mica flake. Therefore, white turbidity happened usually during the process of reaction.

\subsection{Luminescence mechanism of mica-based pearlescent pigment}

Average particle size of crystal $\mathrm{TiO}_{2}$ coating in the surface of mica flake was about $30 \sim 100 \mathrm{~nm}$. According to optical theory, when diameter of solid particle is smaller than half wavelength of visible light, it is transparent. Only transparent nano solid particles could completely reveal the light interference characteristic of films. When visible light( I ) exposed $\mathrm{TiO}_{2}$ film at an incident angle, a part of light( II ) reflected, and other part of light permeate $\mathrm{TiO}_{2}$ film to the surface of mica flake and reflected and transmitted iteratedly. In some certain condition, interference of parallel reflective lights (such as II and III) and parallel transmitted lights(IV and V) occurred, which introduced interference effect(Figure 7).

Single light transmitted by pearlescent pigment was strongly limited, only when the thickness of $\mathrm{TiO}_{2}$ poly-crystal film attained the status of some light with certain wavelength resulting in constructive interference(Maile, 2005, PP. 150-163), and resultant single light was transmitted corresponding to the wavelength(color). Therefore, pearlescent pigment showed lustrous and iridescent due to angle-dependent optical effects deriving from alternating transparent layers with different reflection, refraction and transmission indices, which is the chromophoric essence of magical color pearlescent pigment. Such pigment showed different color based on the corresponding relation between the thickness of $\mathrm{TiO}_{2}$ poly-crystal film and the wavelength of single light, and with the increasing of thickness, gradually showed silvery 
white, golden yellow, red, purple, blue and green. Due to the limit of human eyes' discrimination, pigments with many transitional hue were produced during the process, which was approximately described here.

In the process of preparing pearlescent pigment, the thickness of film is the thinnest. Preparation of silver white pearlescent pigment need the simplest coating technology while its luminescence mechanism was the most complicated. Some researchers(Xu, 2005, PP. 23-26) speculated that it was composed of pigments which reflected a great deal of various color single light, and all these pigments reflecting different colors was distributed even. When the quantity of the single color pigment exceed $50 \%$ of the total pigments, pearlescent pigment showed our eyes not silver white but other colors.

We speculated that aforementioned reason was one of the cardinal factors resulting in silver white of pearlescent pigments, and the color transmitted was associated with the thickness of anatase $\mathrm{TiO}_{2}$ film. Film of silver white was thinner than all other magic color pigments, and its average film thickness failed to attain the status of some light with certain wavelength resulting in constructive interference. Corresponding relation among the hue, wavelength, film thickness and optical thickness were listed in Table 3. According to optical constructive interference theory(Liang, 2008, P. 102) and the first colored pigment, golden yellow pearlescent pigment in the experiment, the thickness ranged from 53.9 58.8nm could transmit single colored light after calculating. Though average thickness failed to achieve the lowest condition of constructive interference, reflectivity of pigments increased enormously and the light intension we saw increased due to the high refractive index of $\mathrm{TiO}_{2}$ poly-crystal film(2.55 of anatase $\mathrm{TiO}_{2}$ and far higher than 1.58 of mica )(Chen, 2006, P. 30), which was an important reason that pearlescent pigment could show silver white luster. On the other hand, due to the irregularity of mica particle size, there was great difference among their specific surface area. In the deposition of meta-titanic acid, under the same reaction condition, $\mathrm{TiO}_{2}$ poly-crystal film was coated irregularly in different mica flake and their optical thickness became more and more discrepant which made pigments tough to obtain pure single colored interference light. Consequently, few pigments with different colored light could be found when silver white pearlescent pigment was observed by ordinary microscope. Mixture of different wavelength light(different colored light) transmitted by pigments was beneficial to the formation of white light transmitted by pearlescent pigment from the global aspect. Taken together, silver white light derived from pearlescent pigment showed be investigated in two aspects.

\section{Conclusions}

Pearlescent pigment with the properties of high crystallinity, good dispersity, no agglomeration and smooth and crackless surface was prepared by hydrothermal method instead of calcination in the present paper. Rules of preparing high performance pearlescent pigment were obtained, described as follows: Increment of temperature and elongation of time during the period of hydrothermal reaction was beneficial to the crystallization of pearlescent pigment. Coating and luminescence mechanism of pearlescent pigment was further discussed based on our observations.

\section{References}

Chen, Z.H., \& Liu, C.H. (2006). Production and application of Titanium dioxides. Beijing: Chemical Industry Press, 30.

Gong, X.Z. (2002). Study on the Mechanism of Mica-Titanium Pearl Pigment. Industrial Minerals \& Processing, (6):13-16.

Li, G.P., \& Luo, Y.J. (2007). Hydrothermal Preparation of ZnS Nanowires. Chinese Journal of Inorganic Chemistry, (11):1864-1868.

Liang, Q.T. (2008). Physical Optics. Beijing: Publishing House of Electronics Industry, 102.

Maile, F.J., Pfaff, G., \& Reynders, P. (2005). Effect Pigments-Past, Present and Future. Progress in Organic Coatings, 54:150-163.

Sun, X.J., \& Li , Z.J. (2004). Chromatics Art of Pearlescent Automobile Paint. Modern Paint \& Finishing, (3):27-29.

Wang, Z.M., Li, Y.M., \& Yang, X.J., et al. (2007). Hydrothermal Synthesis and Crystal Structure of Titanate Nanotubes. Chinese Journal of Inorganic Chemistry, (2):225-230.

Xu, K.Q., Dai, X.Y., \& Chen, S.T. (2002). Synthesis of Rutile-Mica Pearlescent Pigment. Fine Chemicals, (4):227-229.

Xu, Y.Q. (2005). Manufacture Processing and Application of Pearlescent Pigment. Beijing: Chemical Industry Press, 23-26.

Yang, C.Z., Xie, D.C., \& Chen, K.Z. (1989). Phase Diffraction Analysis. Metallurgical Industry Press, :184-189.

Young, C.R., Tae, G.K., \& Guem, S.S., et al. (2008). Effect of Substrate on the Phase Transformation of $\mathrm{TiO}_{2}$ in Pearlescent Pigment. Journal of Industrial and Engineering Chemistry, 14:213-218. 
Table 1. Pigment's crystallization at various times

\begin{tabular}{|l|l|l|l|}
\hline Sample & $4 \mathrm{~h}(\mathrm{a})$ & $8 \mathrm{~h}(\mathrm{~b})$ & $12 \mathrm{~h}(\mathrm{c})$ \\
\hline $\mathrm{Xc}(\%)$ & - & 72.3 & 74.4 \\
\hline
\end{tabular}

Table 2. Pigment's crystallization at different temperature

\begin{tabular}{|l|l|l|l|}
\hline Sample & $180^{\circ} \mathrm{C}(\mathrm{d})$ & $210^{\circ} \mathrm{C}(\mathrm{e})$ & $240^{\circ} \mathrm{C}(\mathrm{f})$ \\
\hline $\mathrm{Xc}(\%)$ & 50.3 & 75.1 & 86.7 \\
\hline
\end{tabular}

Table 3. Corresponding relation among the hue, wavelength, film thickness and optical thickness

\begin{tabular}{|l|l|l|l|}
\hline Hue & $\begin{array}{l}\text { Wavelength } \\
(\mathrm{nm})\end{array}$ & $\begin{array}{l}\text { Film } \\
\text { thickness(nm) }\end{array}$ & $\begin{array}{l}\text { Optical } \\
\text { thickness(nm) }\end{array}$ \\
\hline $\begin{array}{l}\text { Golden } \\
\text { yellow }\end{array}$ & $550 \sim 640$ & $53.9 \sim 58.8$ & $137.4 \sim 149.9$ \\
\hline Red & $640 \sim 780$ & $58.8 \sim 76.5$ & $149.9 \sim 195.1$ \\
\hline Purple & $380 \sim 450$ & $111.8 \sim 132.4$ & $195.1 \sim 337.6$ \\
\hline Blue & $450 \sim 480$ & $132.4 \sim 141.2$ & $337.6 \sim 360.1$ \\
\hline Green & $480 \sim 550$ & $141.2 \sim 161.8$ & $360.1 \sim 412.6$ \\
\hline
\end{tabular}

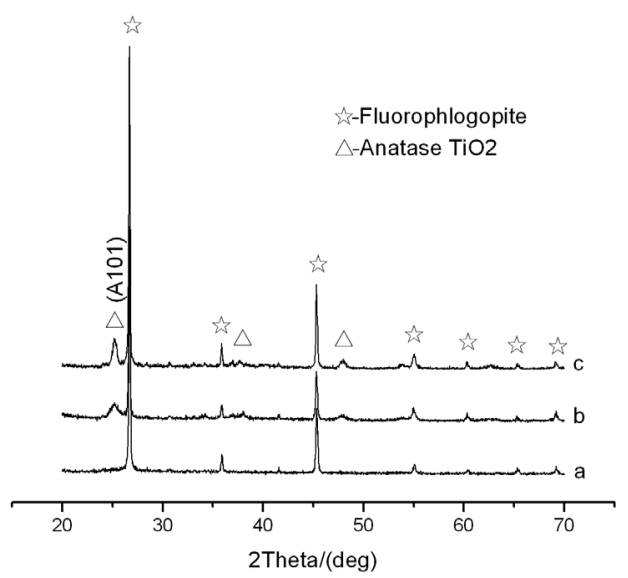

Figure 1. XRD patterns of pigment at various time: (a) $4 \mathrm{~h}$; (b)8h; (c) $12 \mathrm{~h}$ 


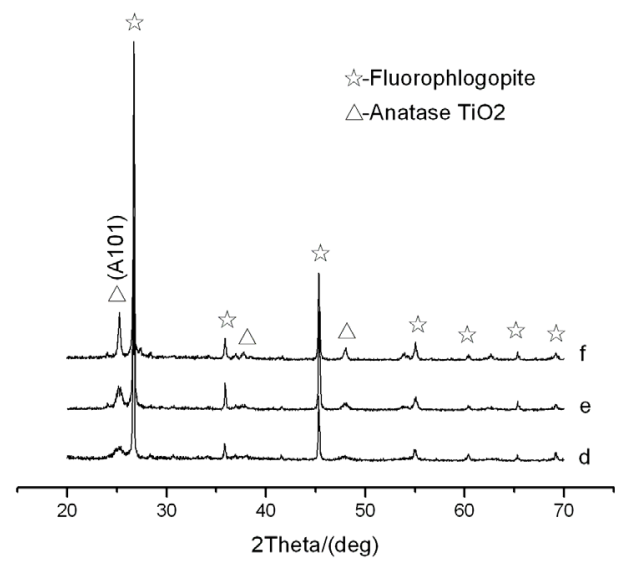

Figure 2. XRD patterns of pigment at different temperature: (d) $180^{\circ} \mathrm{C}$; (e) $210^{\circ} \mathrm{C}$; (f) $240^{\circ} \mathrm{C}$
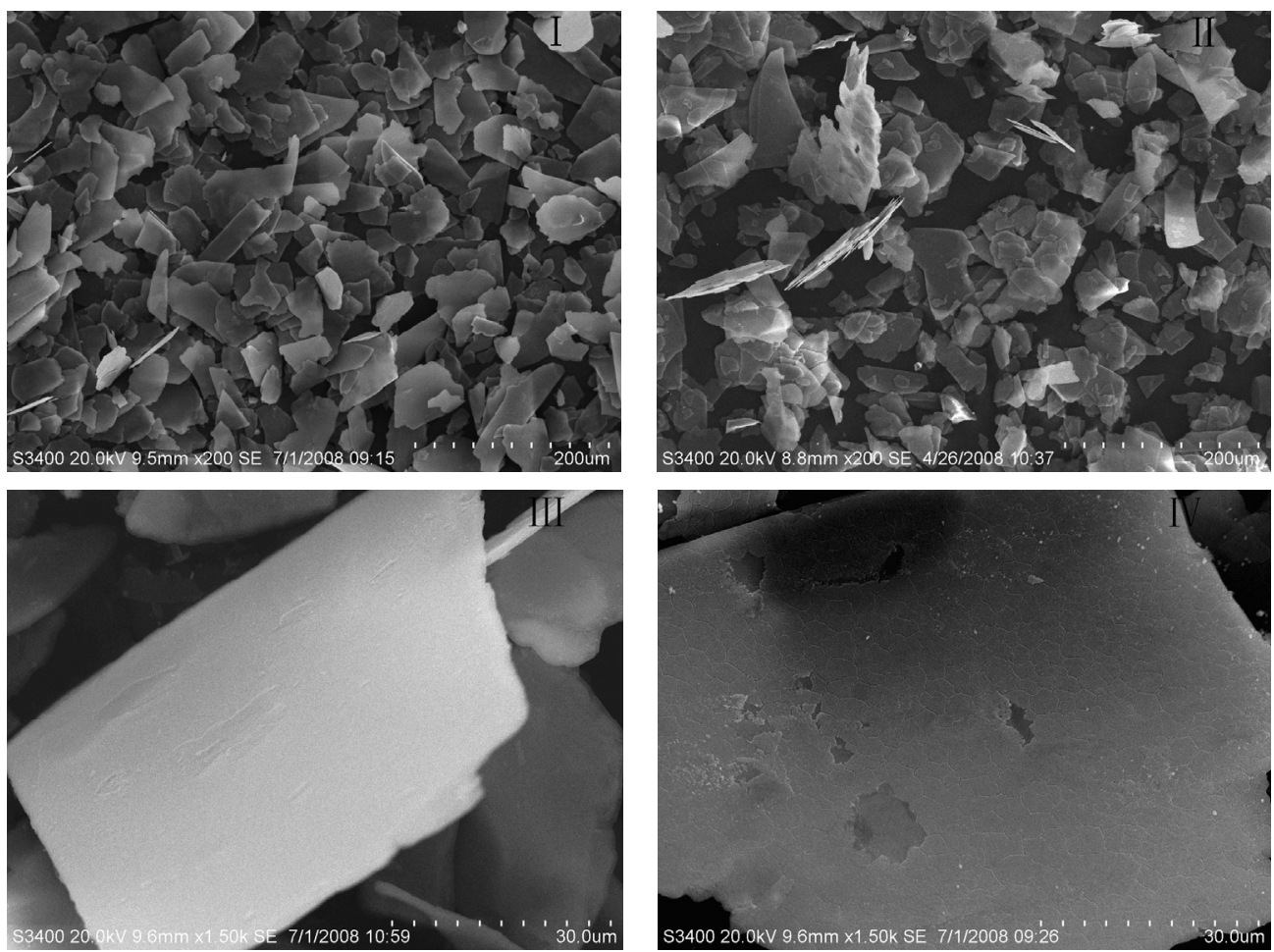

Figure 3. SEM images of pearlescent pigments 


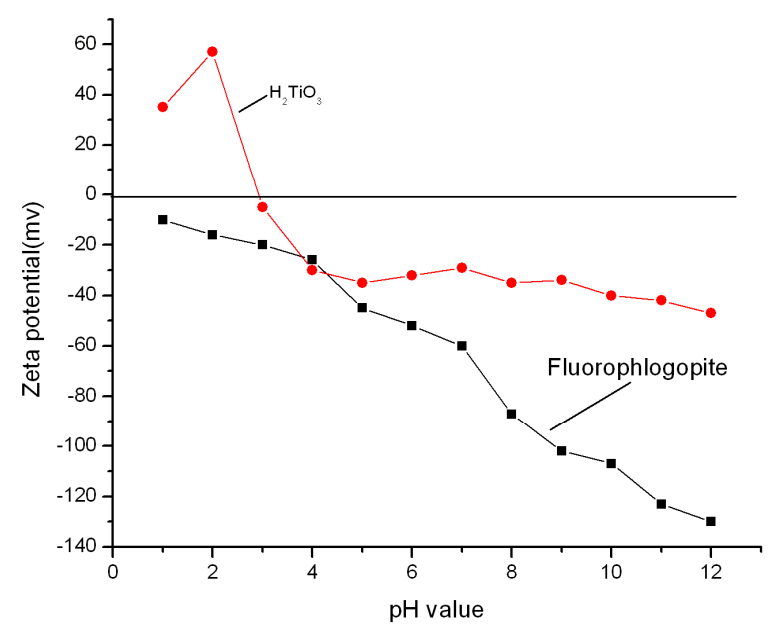

Figure 5. Effects of $\mathrm{pH}$ values on Zeta potential of metatitanic acid particles and fluorophlogopite flake

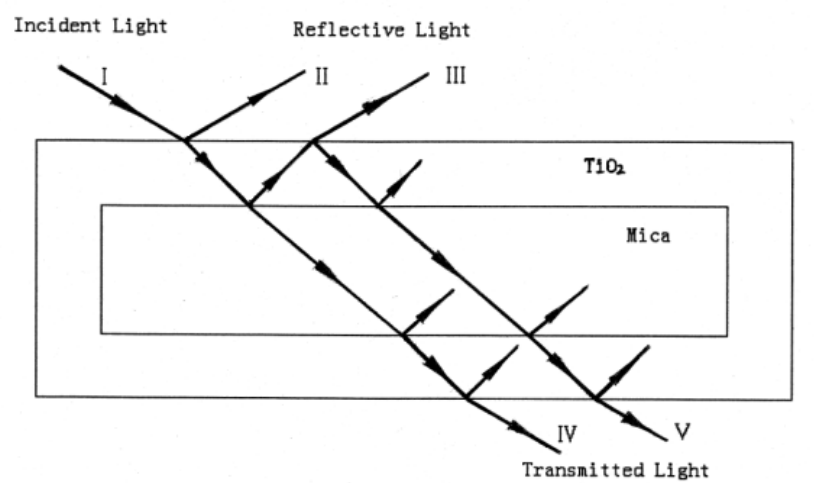

Figure 7. The reflection diagram of mica-based pearlescent pigment 